\title{
Os aspectos ambientais no processo decisório do produtor rural: Estudo de caso Núcleo Rural Taquara
}

\author{
Antonio C. F. Ribeiro ${ }^{1}$, Ricardo S. Brites ${ }^{2} \&$ Ana M. R. Junqueira ${ }^{1}$
}

\begin{abstract}
RESUMO
A pesquisa foi realizada em uma amostra de 75 produtores rurais utilizando-se questionário do tipo estruturado/semiaberto. Verificou-se que o produtor rural decide, sob a luz do modelo econômico vigente, fundamentando suas decisões em elementos voltados à priorização de resultados econômicos, ou seja, a maximização do lucro. Neste sentido, seu processo decisório é conduzido na lógica da obtenção de maior volume de produção ao menor custo, fazendo uso de sua experiência e tradição, da tecnologia disponível e da assistência técnica, atento às condições do clima, à obtenção de um produto de qualidade e às sinalizações do mercado, em especial às relacionadas ao preço. Os aspectos ambientais só são contemplados, de forma prioritária, quando participam ou interferem de forma direta nos resultados econômicos da atividade; caso contrário, o equacionamento de suas questões se resumirá à simples utilização de algumas práticas e procedimentos específicos, considerados suficientes à solução do problema. A incorporação da dimensão ambiental ao processo decisório do produtor rural deve considerar, além da lógica de suas decisões, o papel do Estado como agente indutor de mudanças.
\end{abstract}

Palavras-chave: tomada de decisão, produtores rurais, priorização dos resultados, meio ambiente

\section{The environmental aspects in the farmer's decision process: A case study of Rural Taquara Nucleus}

\begin{abstract}
The research was accomplished in a sample of 75 farmers with the application of an open structured questionnaire. It was verified that farmers decide, under the actual economic model, make their decisions focused on the economic results, that is to say, the maximization of profit. In this sense, their decision is made by the logic of obtaining a larger production at the smallest cost making use of available technology and technical assistance, with regard to climatic conditions, obtaining a good quality product, observing market demands, mainly those related to price. The environmental aspects are only observed with priority when they participate or interfere in a direct way in the economic results, otherwise, the actions are summarised to simple practices and procedures considered enough by farmers to solve the problems. The integralization of environmental aspects in the farmers' decision process besides the logic of their decision must consider the role of State as a promoter of changes.
\end{abstract}

Key words: decision making, farmers, outcome priorization, environmental aspects

${ }^{1}$ Faculdade de Agronomia e Medicina Veterinária/UnB, Campus Universitário Darcy Ribeiro, C. P. 4508, CEP 70910-970, Brasília, DF. Fone: (61) 273-1840. E-mail: acfelix@unb.br; anamaria@unb.br

2 Pós-Graduação em Planejamento e Gestão Ambiental, Universidade Católica de Brasília SGAN 916, módulo B, CEP 70790-160, Brasília, DF. Fone: (61) 340-5550. E-mail: rbrites@pos.ucb.br 


\section{INTRODUÇÃO}

O potencial de danos que pode ser gerado pela atividade agropecuária, faz da mesma uma das principais vilãs do meio ambiente, exigindo da empresa rural, independente do seu tamanho, tipo de atividade e nível de tecnologia, um processo de gestão em que se busque não apenas o atingimento dos seus objetivos empresariais de produção e de obtenção de lucro mas, também, a utilização correta (racional/planejada) dos seus recursos, inclusive os naturais, visando o equilíbrio da atividade e da preservação do meio ambiente.

Esta potencialidade de danos está se intensificando, em diversidade e intensidade, em decorrência dos avanços tecnológicos, utilizados sob a ótica de um modelo econômico de natureza produtivista, que tem como princípio a obtenção de benefícios máximos e imediatos, priorizando o dinheiro (lucro) como única condição de sucesso e geração de riqueza.

Neste quadro, o Brasil busca ocupar posição de destaque como um dos principais produtores mundiais na atividade agropecuária contando, para tanto, com as áreas de cerrado como sua maior e mais importante fronteira.

Apesar da potencialidade agrícola que lhe é atribuída, decorrente de características de clima, água, relevo, solo e, também, à sua grande dimensão em termos de área, as regiões de cerrado apresentam grande vulnerabilidade aos efeitos impactantes da atividade agropecuária, comprometendo seriamente a continuidade desta atividade, pelo esgotamento dos seus recursos naturais, desequilíbrios provocados e conseqüentes danos gerados ao meio ambiente.

Medeiros (2001), analisando o desenvolvimento da agricultura na região do cerrado, afirma que até o início da década de 70 o cerrado era considerado impróprio para a exploração agropecuária, dita "moderna”.

Os avanços tecnológicos proporcionados pela pesquisa agropecuária, dentro da lógica da internacionalização da Revolução Verde, a implementação de políticas e programas governamentais concebidos e implementados nas décadas de 70 e 80, o artifício do crédito agrícola subsidiado e a demanda crescente de uma agricultura comercial voltada para o mercado externo, fizeram com que esta imensa fronteira agrícola fosse incorporada à agricultura brasileira, respondendo, hoje, por considerável parcela da produção agropecuária, especialmente grãos e carne.

A compreensão do processo de modernização da agricultura brasileira nas regiões de cerrado, é de grande importância ao entendimento do processo decisório do produtor rural, pois permite que se identifiquem elementos responsáveis pelo seu direcionamento.

A relação que se pretende fazer deste contexto com a gestão da empresa rural, diz respeito ao engessamento das decisões do produtor, ficando as mesmas condicionadas às políticas e atividades previamente definidas, tidas como prioritárias à compulsoriedade de pacotes tecnológicos e às linhas de crédito amarradas/condicionadas a modelos estabelecidos, restando-lhes apenas decidir sobre o volume de produção a ser obtida e conseqüente expectativa de lucro.

A assistência técnica, também submetida às mesmas condições, desvirtuou-se totalmente dos seus verdadeiros obje- tivos voltando-se quase que exclusivamente para a realização de projetos agropecuários, com vistas à obtenção de financiamento, através do crédito rural.

Esses projetos, se assim podem ser chamados, não passavam de formulários padronizados, preenchidos conforme pacotes tecnológicos preestabelecidos, sem se considerar características e especificidades das propriedades, preocupando-se apenas em assegurar as garantias bancárias do empréstimo contratado.

Segundo Dias (2000), a maior parte dos sintomas de degradação ambiental representa efeitos de tomada de decisões políticas erradas, controversas e afastadas dos interesses comuns da comunidade.

Percebe-se que a conotação de vilã do meio ambiente, pejorativamente atribuída à agropecuária, não é imperativo de sua natureza antrópica, mas, sim, do inadequado uso de sua prática, sem se considerar a utilização racional/planejada dos seus recursos, inclusive os naturais; portanto, de responsabilidade do praticante público e/ou privado que através de políticas, programas, projetos e atividades consideram, equivocadamente, como inevitáveis ou associados à má sorte, atos com conseqüências lesivas ao meio ambiente.

No presente trabalho, parte-se do princípio de que na atividade agropecuária, a utilização correta dos recursos naturais e a preservação do meio ambiente cabem, de forma direta, ao usuário desses recursos o produtor rural e, ainda, que esta questão é essencialmente um problema de gestão; portanto, o produtor rural no exercício de suas atividades é, em síntese, um tomador de decisões, definindo não só seus objetivos, mas, também, os recursos necessários, os meios e formas que deverão ser seguidos para atingi-los.

Considerando-se que o processo de tomada de decisão é o centro do processo administrativo, conforme Vale (1999) buscou-se, neste trabalho, analisar o processo decisório do produtor rural, identificando os elementos que o influenciam e, em especial, se os aspectos ambientais fazem parte do seu consubstanciamento.

\section{MATERIAL E MÉTODOS}

Para o desenvolvimento do trabalho em questão utilizouse o método de Estudo de caso, cuja área foi o Núcleo Rural Taquara, pertencente à região administrativa de PlanaltinaDF, localizado nas microbacias hidrográficas formadas pelos córregos Pipiripau e Jacaré, distando aproximadamente 60 km do Plano Piloto, considerando-se sua representatividade, em termos de atividades agropecuárias desenvolvidas, características de clima, solo, relevo, recursos hídricos típicos de área de cerrado e, em especial, a condição do referido Núcleo ter sido campo de estudo e de pesquisas voltadas à preservação ambiental.

Acredita-se que as questões e problemas levantados não lhe são exclusivos, podendo-se observá-los em diversas regiões produtoras do Distrito Federal e do Brasil.

Para resposta ao principal questionamento indutor deste trabalho, realizou-se uma pesquisa de campo através da aplicação de questionário, do tipo definido por Viegas (1999), 
como estruturado/semi-aberto, ou seja, estruturado por ser formado por perguntas e respostas pré-qualificadas e, semiaberto, em virtude de apresentar no elenco de respostas fechadas, o item “outros” e, se necessário, observações explicativas sobre opção de respostas.

O referido questionário aplicado no período de abril a junho de 2003, teve como princípio os seguintes aspectos:

1. O processo decisório do produtor rural pode, de forma simplificada, ser resumido na busca de respostas para as seguintes questões: O que produzir? Como produzir? Quando produzir? Quanto produzir? E Para quem produzir?;

2. Para cada uma das referidas questões, elencaram-se 12 alternativas, propondo-se a escolha de oito, consideradas pelo entrevistado de maior importância/prioridade ampliando-se, desta forma, a possibilidade de escolha de cada item. Através dos percentuais de escolha foram gerados gráficos com índice de freqüência com o objetivo da visualização dos resultados e sua análise, tendo em vista as alternativas classificadas no terço superior de cada questão.

Para sistematização e análises dos dados, utilizaram-se os aplicativos SPSS (Statistical Package for Social Sciences) e SAS (Statistical Analysis System).

\section{Tamanho da amostra}

Para determinação do número de produtores entrevistados, procedeu-se ao cálculo do tamanho mínimo da amostra, conforme proposto por Barbetta (2001) considerando-se: n - tamanho da amostra (número de produtores necessários para compor a amostra).

$\mathrm{N}$ - tamanho da população (número total de produtores do

Núcleo Rural Taquara).

$\mathrm{n}_{0}$ - uma primeira aproximação para o tamanho da amostra. $\mathrm{E}_{0}$ - erro amostral tolerável.

Adotado nível de confiança de 90\%, tido como satisfatório para este tipo de pesquisa, tem-se que:

$$
\mathrm{n}_{0}=1 /\left(\mathrm{E}_{0}\right)^{2} ; \quad \mathrm{n}_{0}=1 /(0,1)^{2} ; \quad \mathrm{n}_{0}=100
$$

Para

$$
\begin{aligned}
\mathrm{n}_{0} & =100 \\
\mathrm{~N} & =285
\end{aligned}
$$

O tamanho da amostra foi calculado através da seguinte equação:

$$
\begin{gathered}
\mathrm{n}=\left(\mathrm{N} \times \mathrm{n}_{0}\right) /\left(\mathrm{N}+\mathrm{n}_{0}\right), \quad \mathrm{n}=(285 \times 100) /(285+100), \\
\mathrm{n}=74,03 \text { produtores }
\end{gathered}
$$

Diante do universo de 285 produtores rurais existentes no Núcleo Rural Taquara, definiu-se, como 75 produtores, o tamanho mínimo da amostra a ser pesquisada.

\section{RESULTADOS E DISCUSSÃO}

\section{Processo decisório}

A análise das questões básicas que caracterizam o processo de tomada de decisão dos produtores rurais, simplificadamente resumidas a decisões sobre: o que produzir, como, quando, quanto e para quem, permitiu identificar-se os principais elementos utilizados para o seu consubstanciamento, as pri- oridades que lhes são atribuídas e, à luz da teoria administrativa, a compreensão de sua natureza, os aspectos que o influenciam e como este processo se desenvolve.

\section{O que produzir?}

Os elementos considerados de maior importância ao consubstanciamento desta decisão, foram (Figura 1): possibilidade de maior lucro $(98,7 \%)$, experiência e tradição na atividade (86,7\%), mercado (85,3\%) e menor custo de produção, considerado por $72,7 \%$ dos produtores.

\section{O quê produzir}

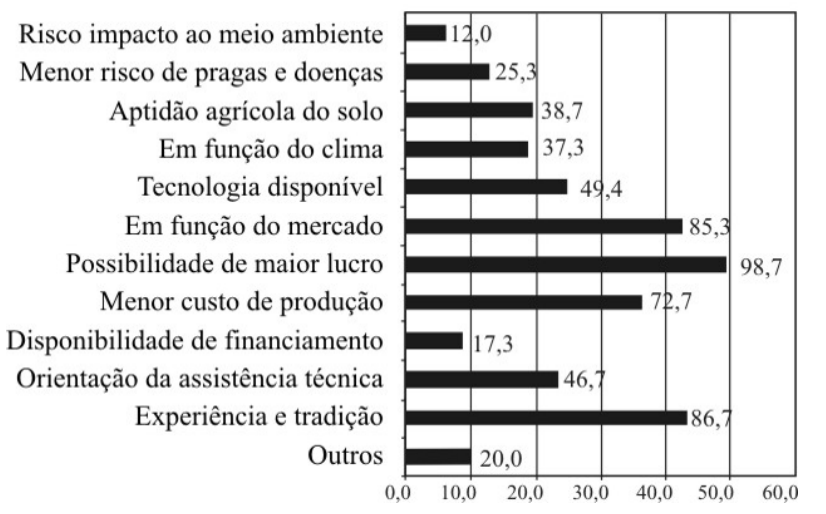

Figura 1. Opções priorizadas pelos produtores do Núcleo Rural Taquara na tomada de decisão sobre o que produzir. Brasília, 2003

Com relação aos aspectos ambientais, a opção/aptidão agrícola do solo ocupou a sétima classificação entre as doze alternativas apresentadas, referenciada por $38,7 \%$ dos produtores pesquisados. A opção risco de impacto ao meio ambiente, foi a menos priorizada, considerada por apenas $12 \%$ dos produtores.

A opção outros, assinalada por $20 \%$ dos produtores, referiu-se ao "gosto pela atividade", representando uma suposta vocação pela mesma, considerada importante na sua decisão sobre o que produzir.

\section{Como produzir?}

Os elementos priorizados para o seu consubstanciamento foram (Figura 2): possibilidade de obtenção de maior produtividade (93,3\%), menor custo de produção (91,9\%), tecnologia

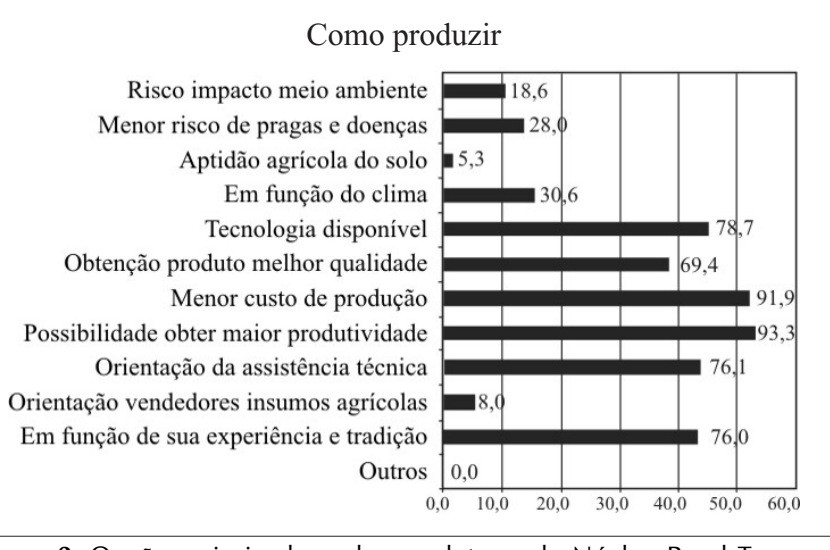

Figura 2. Opções priorizadas pelos produtores do Núcleo Rural Taquara na tomada de decisão sobre como produzir. Brasília, 2003 
disponível (78,7\%) e orientação da assistência técnica (76,1\%) destacando-se, ainda, a opção experiência e tradição (76\%) e obtenção de produto de melhor qualidade $(69,4 \%)$.

\section{Quando produzir?}

Os elementos tidos como de maior importância foram (Figura 3): possibilidade de obtenção de maior produção (85,4\%), clima $(81,4 \%)$, mercado $(78,7 \%)$ e menor custo de produção (77,3\%). Também mereceram destaque os itens: experiência e tradição, possibilidade de obtenção de produto de melhor qualidade e orientação da assistência técnica, citados por 72,0, 62,7 e 62,6\%, respectivamente.



Figura 3. Opções priorizadas pelos produtores do Núcleo Rural Taquara na tomada de decisão, sobre quando produzir. Brasília, 2003

\section{Quanto produzir?}

Os elementos priorizados, foram (Figura 4): possibilidade de obtenção de maior lucro (96\%), custo de produção (92\%), demanda de mercado (90,7\%) e disponibilidade de recursos financeiros, citada por $85,4 \%$ dos entrevistados.

\section{Quanto produzir}

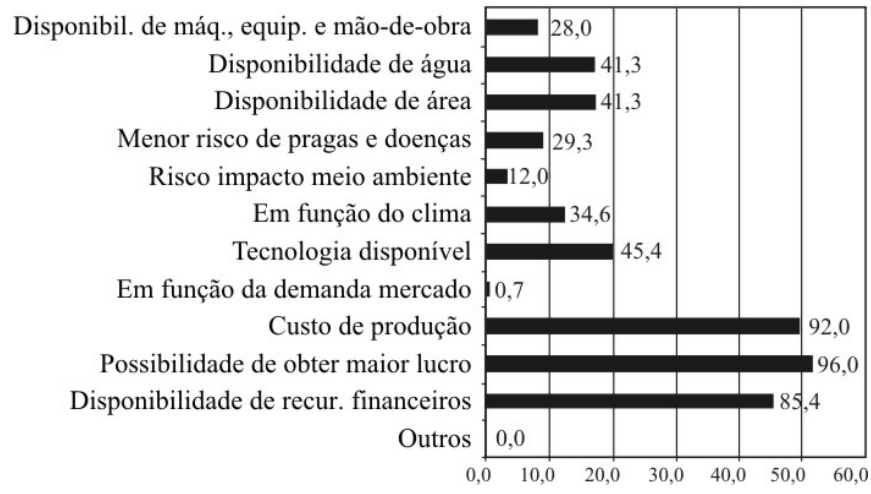

Figura 4. Opções priorizadas pelos produtores do Núcleo Rural Taquara na tomada de decisão, sobre quanto produzir. Brasília, 2003

\section{Para quem produzir?}

Os elementos prioritariamente considerados, foram (Figura 5): obtenção de melhor preço $(98,7 \%)$, mercado que ofereça fidelidade e garantia de compra da produção (90,7\%), menor custo de comercialização (88\%) e merca- do que ofereça condições de maior volume de comercialização (71,9\%) destacando-se, ainda, o item proximidade $(62,7 \%)$.

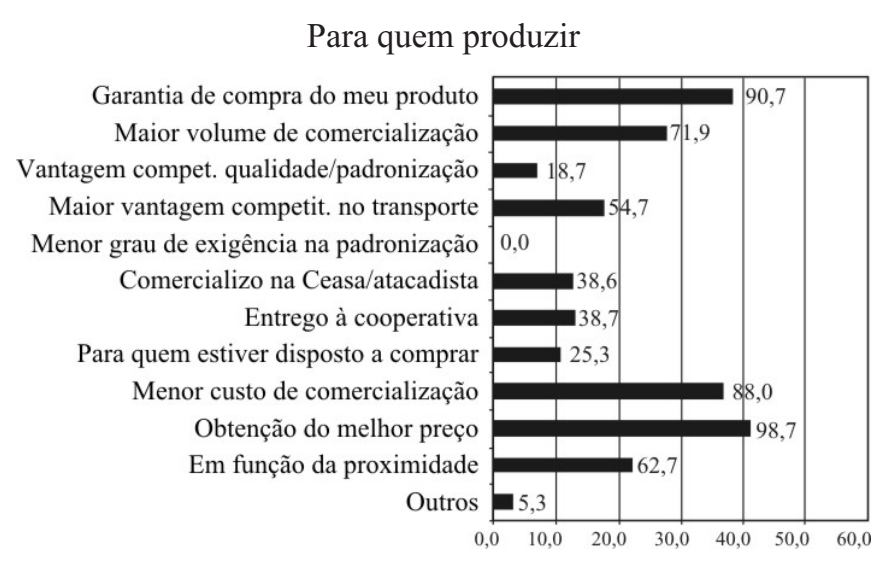

Figura 5. Opções priorizadas pelos produtores do Núcleo Rural Taquara, na tomada de decisão sobre para quem produzir. Brasília, 2003

A opção outros, assinalada por 5,3\% dos produtores, refere-se aos que declararam participar de sistemas integrados de produção e venda de seu produto; por outro lado, as questões ambientais não integram, prioritariamente, o conjunto de elementos que consubstanciam suas decisões chaves. Seu processo decisório é conduzido sob a lógica de obtenção de um volume maior de produção a menor custo, tendo como principal objetivo o lucro contando, neste sentido, com sua experiência e tradição, tecnologia disponível e orientação da assistência técnica, atento às condições do clima, à obtenção de um produto de boa qualidade e às sinalizações do mercado, em especial às relacionadas ao preço.

Uma explicação para este resultado pode ser dada pela teoria administrativa, em especial ao que afirma Vale (1999) sobre a subjetividade da racionalidade das decisões, geralmente definida em função da meta ou do objetivo a ser perseguido e, neste sentido, qualquer decisão que não busque, com máxima eficiência, o seu atingimento, não seria considerada racional. O mesmo autor conclui que, dentro desta linha e à luz do modelo econômico vigente, as decisões racionais tendem a ser voltadas no sentido da maximização do lucro, tendo sido o mesmo observado nesta pesquisa. Se considerado o lucro como principal objetivo do produtor rural, concluir-se-á que as opções maior produção/ produtividade, menor custo de produção, qualidade do produto e tecnologia disponível, representam os meios e formas utilizados para sua obtenção. Neste sentido, Viegas (1996) afirma existirem linhas norteadoras do processo decisório definindo, dentre outras, a conduzida dentro de uma visão econômica, caracterizada por buscar a maximização de uso dos recursos, considerando que as decisões deverão ocorrer em cima de alternativas que proporcionem maiores lucros. Simon (1965) acrescenta que o critério norteador empregado na decisão é, sem dúvida, o da eficiência, representada pela obtenção de resultados máximos relativos a produção, produtividade, diminuição de custos e 
lucro. No sentido de identificar-se esses meios e formas se direcionam apenas a resultados econômicos ou se, também, contemplam o uso correto dos recursos naturais e os aspectos ambientais, analisaram-se os itens priorizados na decisão, sobre como produzir, constatando-se claramente a tendência pela primeira opção.

Corrobora com a explicação apresentada, a análise das práticas agrícolas utilizadas pelos produtores (Tabela 1), estruturada através de dados colhidos no questionário. Quando indagados sobre a adoção de práticas mais diretamente relacionadas à preservação dos recursos naturais, como, por exemplo, o plantio direto, adotada por $85 \%$ dos produtores de grãos, constatou-se que o principal fator indutor da realização desta prática está relacionado ao custo de produção e, conseqüentemente, à racionalidade de maximização do lucro; observou-se ainda, do cruzamento entre a referida prática e a decisão de como produzir, que $94,1 \%$ dos produtores que adotam o plantio direto priorizaram o custo de produção na tomada de decisão.

Evidencia-se, deste modo, o conceito do "homem econômico”, apresentado por Vale (1999), cuja atenção está sempre voltada à busca de meios e formas de maximização do seu principal objetivo, o lucro.

A priorização da experiência e tradição, considerada por $86,7 \%$ dos produtores, no consubstanciamento da decisão sobre o que produzir, confirma o que observam Koontz \& O’Donnell (1981) sobre a tendência do administrador/produtor/decisor atribuir, à sua experiência, um papel maior que o merecido na tomada de decisão. $\mathrm{O}$ mesmo autor salienta também, que as decisões devem ser tomadas face a acontecimentos futuros, ao passo que a experiência pertence ao passado podendo, portanto, não representar um momento futuro. A evidência desses fatos na atividade agropecuária ocorre quando se analisam os conhecidos problemas de equilíbrio entre oferta e deman- da, geralmente induzidos por fatores de natureza sazonal, cíclica ou circunstancial, gerando expectativa equivocada de lucro através do volume de venda e/ou obtenção de preço, provocando estímulos intempestivos de plantio e conseqüentes frustrações de venda do produto decorrente de oferta, muitas vezes, maior que a demanda. Os prejuízos acarretados por este fato não se restringem apenas ao produtor ocorrendo, também, a nível nacional, através do desperdício dos recursos utilizados, inclusive dos naturais, provocando o agravamento dos problemas sociais, descapitalizando o produtor, gerando endividamento e, por vezes, inviabilizando sua permanência na atividade. Mesmo assim, a consideração da experiência e a tradição no processo de tomada de decisão não devem ser invalidadas; exige-se apenas que estas sejam cuidadosamente construídas, criteriosas e continuamente analisadas, através da agregação permanente de novos dados e informações permitindo, deste modo, a identificação de mudanças, percepção de novos cenários e, em especial, a capacidade de se antecipar os problemas e oportunidades.

Pode-se inferir que a experiência e a tradição só assumem efeito positivo se associadas a um processo de gestão que contemple, efetivamente, as funções administrativas de planejamento, organização, direção e controle tendo, nesta última, a base para sua validade e permanente atualização.

Torna-se importante destacar as opções maior produção/ produtividade, priorizadas nas decisões sobre como e quando produzir, cujos resultados apontam para um comportamento de natureza produtivista por parte do produtor rural, caracterizado por prevalecer sobre a racionalidade de uma análise mais detalhada sobre o comportamento do mercado, gerando os já mencionados problemas de oferta e demanda, com conseqüentes impasses de comercialização do produto. Segundo Romeiro (1998), este comportamento

Tabela 1. Práticas agrícolas utilizadas pelos produtores do Núcleo Rural Taquara em função do tipo de atividade, Brasília, 2003

\begin{tabular}{|c|c|c|c|c|c|c|c|c|}
\hline \multirow{3}{*}{ Descrição } & \multicolumn{8}{|c|}{ Tipo de Atividade } \\
\hline & \multicolumn{2}{|c|}{ Produção de Grãos } & \multicolumn{2}{|c|}{ Olericultura } & \multicolumn{2}{|c|}{ Fruticultura } & \multicolumn{2}{|c|}{ Produção Animal } \\
\hline & $\mathrm{N}^{0}$ & $\%$ & $\mathbf{N}^{0}$ & $\%$ & $\mathrm{~N}^{0}$ & $\%$ & $\mathrm{~N}^{0}$ & $\%$ \\
\hline Construção de terraços & 16 & 80,0 & 0 & 0,0 & 02 & 33,3 & 03 & 21,4 \\
\hline Plantio em nível & 20 & 100,0 & 35 & 100,0 & 06 & 100,0 & 14 & 100,0 \\
\hline Adubação verde & 07 & 35,0 & 0 & 0,0 & 0 & 0,0 & 0 & 0,0 \\
\hline Plantio direto & 17 & 85,0 & NA & NA & NA & NA & NA & NA \\
\hline Cultivo orgânico & 0 & 0,0 & 0 & 0,0 & 0 & 0,0 & 01 & 7,1 \\
\hline Hidroponia & NA & NA & 0 & 0,0 & NA & NA & NA & NA \\
\hline Irrigação & 03 & 15,0 & 35 & 100,0 & 02 & 33,3 & 02 & 14,2 \\
\hline Uso sistemático de defensivos agrícolas & 16 & 80,0 & 35 & 100,0 & 06 & 100,0 & 13 & 92,8 \\
\hline Controle biológico de pragas & 06 & 30,0 & 03 & 8,5 & 01 & 16,7 & 01 & 7,1 \\
\hline Rotação de culturas & 17 & 85,0 & 28 & 80,0 & NA & NA & 01 & 7,1 \\
\hline Rotação de pastagem & NA & NA & NA & NA & NA & NA & 07 & 50,0 \\
\hline Queimadas & 0 & 0,0 & 0 & 0,0 & 0 & 0,0 & 02 & 14,3 \\
\hline Aceiro contra fogo & 20 & 100,0 & 20 & 57,1 & 06 & 100,0 & 14 & 100,0 \\
\hline Desmatamento & 0 & 0,0 & 0 & 0,0 & 0 & 0,0 & 0 & 0,0 \\
\hline Aração & 20 & 100,0 & 35 & 100,0 & 06 & 100,0 & 14 & 100,0 \\
\hline Gradagem & 20 & 100,0 & 35 & 100,0 & 06 & 100,0 & 14 & 100,0 \\
\hline Subsolagem & 16 & 80,0 & 0 & 0,0 & 0 & 0,0 & 05 & 35,7 \\
\hline
\end{tabular}

NA = Não se aplica 
é fruto das políticas agrícolas adotadas nestas últimas quatro décadas, que levaram o produtor a supor que o sucesso de sua atividade estava condicionado simplesmente à obtenção de um volume maior de produção a um custo menor.

Quanto à opção tecnologia disponível, também priorizada para o consubstanciamento da decisão de como produzir, confirma-se o fato já diagnosticado pela EMATER, conforme SEAPA/EMATER (2001), que aponta a posição de destaque do Núcleo Rural Taquara quanto a este aspecto no Distrito Federal e, possivelmente, no País.

Com relação aos aspectos ambientais, verificou-se que a predisposição para a adoção de práticas voltadas ao uso correto dos recursos naturais e a preservação do meio ambiente, está sempre associada a resultados econômicos perceptíveis. A teoria da decisão identifica três níveis de ganho perceptíveis pelos decisores/produtores, os chamados ganhos diretos: aumento de produtividade e melhoria da qualidade do produto; os de diminuição de custo: plantio direto e a prática da cobertura morta e, por fim, os relacionados à superação de fatores contrários à realização de um objetivo, definido por Koontz \& O’Donnell (1981) como de natureza restritiva ou crítica. Para este último, dois exemplos esclarecedores foram observados nesta pesquisa, em que o primeiro está relacionado à disponibilidade de água de irrigação para os produtores de hortaliças. Ante a sua limitação, uso compartilhado e controlada distribuição, decidiu-se pela tecnologia de irrigação localizada (gotejamento) despertando nos usuários os cuidados necessários à preservação deste valioso recurso natural.

Outro exemplo, também relacionado à olericultura, diz respeito à decisão sobre a determinação dos locais de cultivo. Há aproximadamente dez anos eram escolhidas, para o cultivo de hortaliças, áreas de baixada, localizadas próximo aos cursos de água ocupando, por vezes, áreas de matas ciliares, tirando proveito não só de uma estrutura melhor do solo mas, também, da facilidade de irrigação. Hoje, o cultivo de hortaliças foi deslocado para solos de cerrado (latossolo), situados em locais mais distantes dos solos hidromórficos, das matas ciliares e dos cursos de água, não por questões ambientais voltadas à preservação desses recursos mas, sim, por questões fitossanitárias, decorrentes da incidência de doenças, em especial nematóides, limitando o desenvolvimento da atividade e comprometendo seu resultado econômico.

O curioso deste fato é que, passado o interesse de cultivo nessas áreas observou-se, por parte dos produtores, toda uma preocupação, não só de preservação das matas ciliares remanescentes, mas, também, de recuperação das que foram destruídas ponderando-se, entretanto, sobre a necessidade de apoio financeiro e considerando os custos inerentes à sua realização. Depreende-se que o principal fator indutor deste comportamento foi, sem dúvida, a busca de preservação da água, necessária à sua produção irrigada.

\section{CONCLUSÕES}

1. O produtor rural decide utilizando, no consubstanciamento de suas decisões, elementos voltados à priorização de resultados econômicos, ou seja, a maximização do lucro.

2. O processo decisório é conduzido sob a lógica da obtenção de um volume maior de produção a menor custo, (fazendo uso de sua experiência e tradição, da tecnologia disponível e da assistência técnica, atento às condições do clima, à obtenção de um produto de qualidade e às sinalizações do mercado, em especial às relacionadas ao preço.)

3. Os aspectos ambientais só são contemplados/priorizados quando, de maneira perceptível, participam ou interferem de forma direta nos resultados econômicos da atividade.

4. A preocupação de não colocar o produtor rural na condição de réu, mas sim, na condição de peça chave de um processo, merecendo especial atenção e maiores cuidados, cabendo-lhe a responsabilidade de execução da prática das ações, na justa proporção dos meios e condições que lhe forem disponibilizados.

5. A incorporação da dimensão ambiental ao processo decisório do produtor rural deverá considerar: a) a lógica de suas decisões; b) a influência sofrida através da dinâmica da evolução histórica da agricultura brasileira e do modelo econômico vigente; c) o desenvolvimento de sua percepção para as questões ambientais; d) a necessidade de capacitá-lo para a gestão da propriedade rural contemplando, neste processo, as questões ambientais; e) o papel do estado como agente indutor de mudanças, cuja presença se torna indispensável, atuando na forma de estímulos, considerando-se sua responsabilidade com o passado, com a condição do presente e necessidades futuras.

\section{LITERATURA CITADA}

Barbetta, P. A. Estatística aplicada às ciências sociais. 4.ed. Florianópolis: UFSC, 2001. 838p.

Dias, G. F. Fundamentos da educação ambiental. Brasília: Universa, 2000. 198p.

Koontz, H.; O’ Donnell, C. Fundamentos da administração. Malferrari, C. A. (trad.). São Paulo: Livraria Pioneira, 1981. 580p.

Medeiros, J. X. Agricultura e agronegócio. Brasília: ABEAS, 2001. 45p.

Romeiro, A. R. Meio ambiente e dinâmica de inovação na agricultura, São Paulo: Annablume: FAPESP, 1998. 272p.

SEAPA/EMATER (Taquara). Principais atividades agropecuárias, 2001. Brasília: EMATER, 2002. 35p.

Simon, H. A. Comportamento administrativo. Rio de Janeiro: Fundação de Cultura, 1965. 278p.

Vale, S. M. L. R. Noções gerais de administração rural. Brasília: ABEAS, 1999. 34p.

Viegas, W. Processo decisório criativo. Brasília: UnB, 1996. 49p.

Viegas, W. Fundamentos de metodologia científica. Brasília: UnB, 1999. 251p. Paralelo 15 